\section{Screening Eucalyptus Clones for Salt Tolerance}

\author{
C.M. Grieve, M.R. Guzy, J.A. Poss, and M.C. Shannon \\ U.S. Department of Agriculture, Agricultural Research Service, U.S. Salinity \\ Laboratory, 450 W. Big Springs Road, Riverside, CA 92507-4617
}

Additional index words. agroforestry, biomass production, coppicing, drainage water reuse, Eucalyptus camaldulensis, E. rudis, relative growth rate, salinity, sulfate-dominated irrigation waters

\begin{abstract}
Agroforestry plantations offer environmentally acceptable strategies for the reuse of saline drainage waters. Tree species suitable for use in such systems must be selected for survival and sustained growth under highly saline conditions. In this screening trial, four clones of Eucalyptus camaldulensis Dehn. (4543, 4544, 4573, and 4590) and one clone of $E$. rudis Endl. (4501) were grown in greenhouse sand cultures irrigated with sodium sulfate-dominated waters. Solution compositions were prepared to simulate saline drainage waters typically found in the San Joaquin Valley of California. Electrical conductivities of the solutions ranged from 2 to $28 \mathrm{dS} \cdot \mathrm{m}^{-1}$. Treatments were replicated three times. All plants survived and were harvested after 7 weeks under saline treatment. Plant height was measured weekly and shoot biomass was determined at final harvest. The salinity levels that resulted in a 50\% reduction in biomass production $\left(C_{50}\right)$ were 16.4 (4573), 17.1 (4543), 17.7 (4544), 29.0 (4590), and $30.0 \mathrm{dS} \cdot \mathrm{m}^{-1}(4501)$. Over the range of salinities from 4 to $20 \mathrm{dS} \cdot \mathrm{m}^{-1}$, clones 4501,4590 , and 4573 generally maintained higher relative growth rates (RGR) than did clones 4544 and 4543 . However, at the highest salinity, RGRs of clones 4501,4544 , and 4573 were significantly greater than those of clones 4543 and 4590 . Assessed on the basis of biomass production, clones 4501 (E. rudis) and 4590 (E. camaldulensis) showed exceptional potential for use in agroforestry systems where the saline drainage waters are sodium sulfate-dominated.
\end{abstract}

Drainage water reuse has been promoted as an environmentally sound method for the disposal of saline drainage water (Rhoades, 1989). A multiple-use approach has been advocated to conserve water, reduce drainage water volume, and minimize the use of otherwise arable land for the construction of temporary disposal facilities, such as evaporation ponds (Cervinka, 1994; Shannon and Grieve, 1999). In this system, selected crops would be grown and irrigated in sequence, starting with very salt-sensitive species, and continuing with increasingly salt-tolerant crops. The drainage water becomes progressively more saline as each successive crop is irrigated. Water recovered from the most salt-tolerant agronomic crop could be used to irrigate agroforestry plantations (San Joaquin Valley Drainage Program, 1990). Suitable tree species for this phase of the saline drainage water reuse system must possess several desirable traits, including high water use, tolerance to salinity, tolerance to waterlogging, high nutrient uptake rate, and, ideally, rapid production of a marketable product. Species selection must be

\footnotetext{
Received for publication 4 Nov. 1998. Accepted for publication 4 Jan. 1999. We are indebted to J.H. Draper and T.J. Donovan for technical assistance. This research was funded by the California Dept. of Water Resources (DWR B-59922), Project Manager, Dr. Fawzi Karajeh. The cost of publishing this paper was defrayed in part by the payment of page charges. Under postal regulations, this paper therefore must be hereby marked advertisement solely to indicate this fact.
}

based primarily on the predicted long-term root-zone salt concentration, along with the possibility that waterlogging may interact with salinity to further increase plant stress. In addition, species should be tolerant to nutrient imbalances, as well as to specific ion toxicities (Marcar and Crawford, 1996; Marcar et al., 1990).

Eucalypts have a capacity for high water use because they often grow rapidly when planted in new environments (see, for example, Eldridge et al., 1993). One notable example of the successful use of eucalypts for evapotranspiration purposes is their use during the 19th century to drain the Pontine Swamps near Rome, a region that had been a malarial swamp since Roman times (Allender, 1990). In addition to water use applications, eucalypts have wide adaptation to many adverse environments, and occur naturally within or near coastal or inland sites of Australia where soils or groundwaters are saline and soils are generally nutrient-poor. Depending on the geographic origin of seed source (provenance), E. camaldulensis exhibits good tolerance to such stresses as salinity, drought, low temperatures, and prolonged inundation (Donaldson et al., 1983; Farrell et al., 1996a, $1996 \mathrm{~b}$ ). The $\mathrm{LD}_{50}$ value (the salinity at which tree survival is reduced by $50 \%$ ) has been reported as $400 \mathrm{~mm} \mathrm{NaCl}\left(\approx 38 \mathrm{dS} \cdot \mathrm{m}^{-1}\right)$ for $E$. camaldulensis seedlings grown in greenhouse solution cultures from seed collected from 10 lacustrine sites in western Victoria (Blake, 1981).

Considerable genetic diversity can exist within seed sources of E. camaldulensis be- cause of generally high outcrossing rates, and, in addition, individuals of this species can hybridize naturally with those of some other species (Eldridge et al., 1993). Therefore, high levels of genetic variation in salt tolerance might be expected in evaluation trials. This inherent variability was emphasized by Thomson (1988), who conducted an evaluation of 53 seed sources from the natural range of E. camaldulensis. The mean salinity causing mortality of seedlings grown in solution cultures ranged from 358 to $636 \mathrm{~mm} \mathrm{NaCl}$. Furthermore, trees derived from initially uniform seedlings chosen for high growth rate may differ by 2 - or 3-fold in growth rate after transplanting to the field (Low et al., 1983). This intraspecific variability has been exploited, and individuals selected for the desired trait(s) (e.g., salt tolerance, high growth rate) have been propagated vegetatively, and maintained as clonal lines (Low et al., 1983).

As tolerance to salinity may not be compatible with other desirable quantitative traits (e.g., high growth rate, high water use, rapid biomass production, marketable product), investigators should make final selections by screening the clonal lines under saline conditions.

The objectives of this study were to evaluate survival, biomass production, and coppicing ability of four clonal lines of $E$. camaldulensis and one selection of $E$. rudis grown under saline conditions in greenhouse sand cultures.

\section{Materials and Methods}

The following eucalypt clones were selected for this study to confirm field performance observations of their salt tolerance (V. Cervinka, F. Menezes, personal communication): 4501 (E. rudis), 4543, 4544, 4573, and 4590 (all E. camaldulensis). Clonal ramets, derived from micropropagation, were obtained from Twyford Plant Laboratories, Santa Paula, Calif. One ramet of each clone was planted into each of 24 sand tanks in a greenhouse on 24 May 1995. Mean shoot height at the time of transplanting was $50 \mathrm{~cm}$. The tanks $(1.2 \times 0.6$ $\times 0.5 \mathrm{~m}$ deep) contained washed sand having an average bulk density of $1.4 \mathrm{Mg} \cdot \mathrm{m}^{-3}$. At saturation, the sand had an average volumetric water content of $0.34 \mathrm{~m}^{3} \cdot \mathrm{m}^{-3}$. Plants were irrigated three times daily with a base nutrient solution (BNS), made up with city of Riverside municipal water, consisting of (in $\mathrm{mol} \cdot \mathrm{m}^{-3}$ ): $2.5 \mathrm{Ca}^{2+}, 1.25 \mathrm{Mg}^{2+}, 15 \mathrm{Na}^{+}, 3 \mathrm{~K}^{+}, 6.9 \mathrm{SO}_{4}{ }^{2-}, 7.0$ $\mathrm{Cl}^{-}, 5.0 \mathrm{NO}_{3}^{-}, 0.17 \mathrm{KH}_{2} \mathrm{PO}_{4}, 0.050 \mathrm{Fe}$ as sodium ferric diethylenetriamine pentaacetate (NaFeDTPA), $0.023 \mathrm{H}_{3} \mathrm{BO}_{3}, 0.005 \mathrm{MnSO}_{4}$, $0.0004 \mathrm{ZnSO}_{4}, 0.0002 \mathrm{CuSO}_{4}$, and 0.0001 $\mathrm{H}_{2} \mathrm{MoO}_{4}$. This BNS served as the control treatment. Each irrigation was of 15 min duration, which allowed the sand to become completely saturated, after which the solution drained into 765-L reservoirs for reuse in the next irrigation. Water lost by evapotranspiration was replenished automatically each day to maintain constant osmotic potentials in the solutions.

Three weeks after the ramets were transplanted, eight salinity treatments were imposed with sulfate-dominated irrigation wa- 
ters designed to simulate saline drainage waters commonly present in the San Joaquin Valley of California, and compositions of increased salinity that would result from further concentration of these drainage waters (Table 1). Electrical conductivities $\left(\mathrm{EC}_{\mathrm{i}}\right)$ of the saline treatments were increased to the desired levels by incremental additions of the salts over five consecutive days to avoid osmotic shock to the plants. Targeted $\mathrm{EC}_{\mathrm{i}}$ values of the solutions were 2 (BNS only), 4, 8, 12, 16, 20, 24, and 28 $\mathrm{dS} \cdot \mathrm{m}^{-1}$. The $\mathrm{pH}$ of the solutions was not controlled and ranged from 7.7 to 8.0. The experiment was a randomized block design with eight salinities, five eucalypt clones, and three replications.

Temperature, radiation, and humidity were measured at hourly intervals at a point slightly above the plant canopy. During the study, greenhouse air temperatures ranged from 22 to $43{ }^{\circ} \mathrm{C}$ (mean $=32.5^{\circ} \mathrm{C}$ ) during the day and from 14 to $22^{\circ} \mathrm{C}\left(\right.$ mean $\left.=18.6^{\circ} \mathrm{C}\right)$ during the night. Relative humidity ranged from $43 \%$ to $52 \%$, with a mean of $46.1 \%$ during the day and $49.2 \%$ during the night.

Plant heights in $\mathrm{cm}( \pm \mathrm{SD})$ for the five clones at the start of salinization treatments were: 4501, 50 (4.9); 4543, 68 (5.0); 4544, 56 (3.1); 4573, 51 (2.9); 4590, 66 (4.1). Thereafter, plant height and stem diameter were measured weekly.

Visual observations of salt toxicity damage and nutrient deficiency (Dell, 1995) were made on a daily basis. Seven weeks after the initiation of salinization, entire shoots were harvested by cutting $\approx 10 \mathrm{~cm}$ above the surface of the sand to leave four or five nodes on the stump. Irrigation treatments were continued for an additional 6 weeks to determine coppicing ability and survival. At harvest, leaves, branches, and main stem portions were separated, washed with deionized water, dried, and weighed to determine total shoot biomass per sapling.

Ion analysis. The irrigation waters were analyzed at weekly intervals by inductively coupled plasma optical emission spectrometry (ICPOES) to confirm that target concentrations of $\mathrm{Ca}^{2+}, \mathrm{Mg}^{2+}, \mathrm{Na}^{+}, \mathrm{K}^{+}, \mathrm{S}$, and $\mathrm{P}$ were maintained. Chloride was determined by coulometric-amperometric titration.

Statistical analysis. Mean relative growth rates based on plant height were calculated for each clone. For each replicate of the experiment, relative growth rates were calculated for each clone within each EC treatment using the formula:

$$
R G R_{j}=\frac{\operatorname{In}\left(h t_{i+2}\right)-\operatorname{In}\left(h t_{i}\right)}{c d d_{i+2}-c d d_{i}}
$$

for each pair of observations $(i=1 . .6$, from 13 June to 31 July), where ht is shoot height and cdd is cumulative degree days. Values of RGR were calculated from alternate observations rather than successive observations to minimize fluctuations in calculated RGR values caused by autocorrelation of statistics at temporally adjacent observations (Poorter, 1989). Next, a weighted mean over time of these RGR values was calculated for each replicate

Table 1. Composition $\left(\mathrm{mol} \cdot \mathrm{m}^{-3}\right)$ of salinizing salts in waters used to irrigate eucalyptus clones.

\begin{tabular}{lrrrrrr}
\hline \hline $\begin{array}{l}\mathrm{EC}_{\mathrm{i}} \\
\left(\mathrm{dS} \cdot \mathrm{m}^{-1}\right)\end{array}$ & {$[\mathrm{Ca}]$} & {$[\mathrm{Mg}]$} & {$[\mathrm{Na}]$} & {$[\mathrm{K}]$} & {$\left[\mathrm{SO}_{4}\right]$} & {$[\mathrm{Cl}]$} \\
\hline 2.0 & 2.6 & 1.6 & 13.8 & 3.0 & 7.0 & 7.0 \\
4.1 & 4.4 & 3.3 & 29.1 & 3.0 & 14.8 & 14.1 \\
7.9 & 8.2 & 6.6 & 58.2 & 3.0 & 29.6 & 28.2 \\
11.9 & 12.6 & 10.0 & 88.5 & 3.0 & 44.9 & 42.9 \\
16.0 & 13.5 & 15.5 & 137.0 & 3.0 & 63.7 & 66.4 \\
20.1 & 13.5 & 20.1 & 178.0 & 3.0 & 79.0 & 86.3 \\
23.9 & 13.7 & 26.5 & 235.0 & 3.0 & 100.0 & 105.0 \\
28.0 & 14.0 & 31.8 & 282.0 & 3.0 & 118.0 & 126.0 \\
\hline
\end{tabular}

of clone $\times$ salt combination. Each weight was calculated as:

$$
\text { Weight }_{j}=\frac{\left(c d d_{j+2}-c d d_{j}\right)}{\sum_{\mathrm{i}}\left(c d d_{i+2}-c d d_{i}\right)}
$$

Finally, a mean RGR over replicates was calculated for each clone $\times$ salt combination.

The exponential equation of van Genuchten and Hoffman (1984) was used to determine shoot biomass yield:

$$
\mathrm{Y}=\mathrm{Y}_{\mathrm{m}} \exp \left(\alpha E C_{\mathrm{i}}-\beta E \mathrm{C}_{\mathrm{i}}{ }^{2}\right)
$$

where $\mathrm{Y}_{\mathrm{m}}$ is the yield under nonsaline conditions, $\mathrm{EC}_{\mathrm{i}}$ is the average electrical conductivity of the irrigation water salinity expressed in $\mathrm{dS} \cdot \mathrm{m}^{-1}$, and $\alpha$ and $\beta$ are empirical constants. Shoot biomass- $\mathrm{EC}_{\mathrm{i}}$ curves were fitted to absolute biomass and corresponding $\mathrm{EC}_{\mathrm{i}}$ data to produce estimates of the $Y_{m}, \alpha$, and $\beta$ in Eq. 3 . The relative values were calculated by defining the estimated value of $Y_{m}=1$. Confidence intervals $(95 \%)$ for the equation and upper and lower boundaries were estimated for the expected mean value, and include the variance of the error as well as the variance of the parameter estimates (SAS Institute, 1985). The salinity values that resulted in $50 \%$ reduction in biomass production $\left(\mathrm{C}_{50}\right)$ were calculated for each clone from Eq. 3 where $\mathrm{Y} / \mathrm{Y}_{\mathrm{m}}=0.5$.

Growth analysis based on final plant height was calculated with the reformulated logistic growth equation described by Thornley (1990):

$$
x=\frac{\left(x_{i}+\frac{\mu_{1}}{b \mu_{2}}\right) x_{i}}{x_{i}+\frac{\mu_{1}}{b \mu_{2}} \exp \left[-\left(\mu_{1}+b \mu_{2} x_{1}\right) t\right]}+\varepsilon
$$

where $x$ is final plant height; $t$, cumulative thermal time; $b, \mathrm{EC}_{\mathrm{i}}$ raised to the power $3 / 2$. The fitted parameters $x_{\mathrm{i}}, \mu_{1}$, and $\mu_{2}$, represent initial height, intrinsic growth rate, and sensitivity of the growth rate to salinity, respectively. In order to compare clones, Eq. 4 was extended to 15 parameters so that each clone had its own $\mu_{1}, \mu_{2}$, and $\mathrm{x}_{\mathrm{i}}$. Standard statistical procedures were used to test for lack of fit, and to test the significance of clone-specific parameters (Myers, 1990).

\section{Results}

Leaves of E. camaldulensis clones 4543, 4544 , and 4573 bore striking similarity to each other. They were grayish-green and were larger (elliptic), thicker, and more schlerophyllous than those of either 4590, a clonal line of the same species, or 4501, E. rudis. Leaves of 4501 and 4590 were orbicular to obovate and non-glaucous. The wide differences in leaf morphology and anatomy of E. camaldulensis have been related to significant provenance variations in Australian trials (James and Bell, 1995). The northern provenances of $E$. camaldulensis generally have more glaucous foliage than do provenances of the same species of southern origin (Allender, 1990).

At the end of the 7 weeks under salinity treatment, all the plants survived and none showed visible signs of salt injury, ion toxicity, or nutrient deficiency disorders as illustrated by Dell (1995).

Foliage of the clonal ramets contributed most to aboveground biomass. Under control conditions, between 56\% (4590) and 66\% (4543) of total shoot biomass was allocated to the leaves, and salinity $\left(28 \mathrm{dS} \cdot \mathrm{m}^{-1}\right)$ increased these percentages to $66 \%(4590)$ and $73 \%$ (4543) (data not shown).

Analysis of the biomass data showed that the clones could be divided into two distinct groups based on $\mathrm{C}_{50}$ values (Fig. 1A-E). Values for clones 4573,4543 , and 4544 were 16.4 , 17.1 , and $17.7 \mathrm{dS} \cdot \mathrm{m}^{-1}$ with coefficients of determination $\left(r^{2}\right)$ of $0.84,0.84$, and 0.82 , respectively.

In comparison, biomass production by clones of 4501 and 4590 was more variable $\left(r^{2}\right.$ $=0.49)$ and $C_{50}$ values were higher at 29.0 and $30.0 \mathrm{dS} \cdot \mathrm{m}^{-1}$, respectively.

Despite the use of clonal material, variability in biomass production within salinity treatment differed depending on the clone. Clone 4544 had the most uniform response (Cv 13.2; Fig. 1A); whereas clones 4501 (CV 20.6; Fig. 1B) and 4590 (Cv 21.8; Fig. 1C) were the most variable. Coefficients of variation for the other clones were 18.8 and 19.6 for clones 4543 and 4573, respectively (Fig. 1 D and E). Coefficients of variation for plant height were: 4501 (7\%); 4543 and 4544 (8\%); $4573(5 \%)$; and $4590(7 \%)$.

Analysis of plant height data with the reformulated logistic model (Thornley, 1990) also ranked clones 4501 and 4590 as least sensitive to salinity.

Relative shoot growth rate of all clones decreased with increasing salinity (Fig. 2). At salinity levels up to $20 \mathrm{dS} \cdot \mathrm{m}^{-1}$, growth rates of clone 4543 and 4544 were generally lower than those of the other three clones. However, clone 4544, along with 4501 and 4573, maintained significantly higher relative growth rates at $28 \mathrm{dS} \cdot \mathrm{m}^{-1}$ than did 4543 and 4590.

Based on both final shoot biomass mea- 

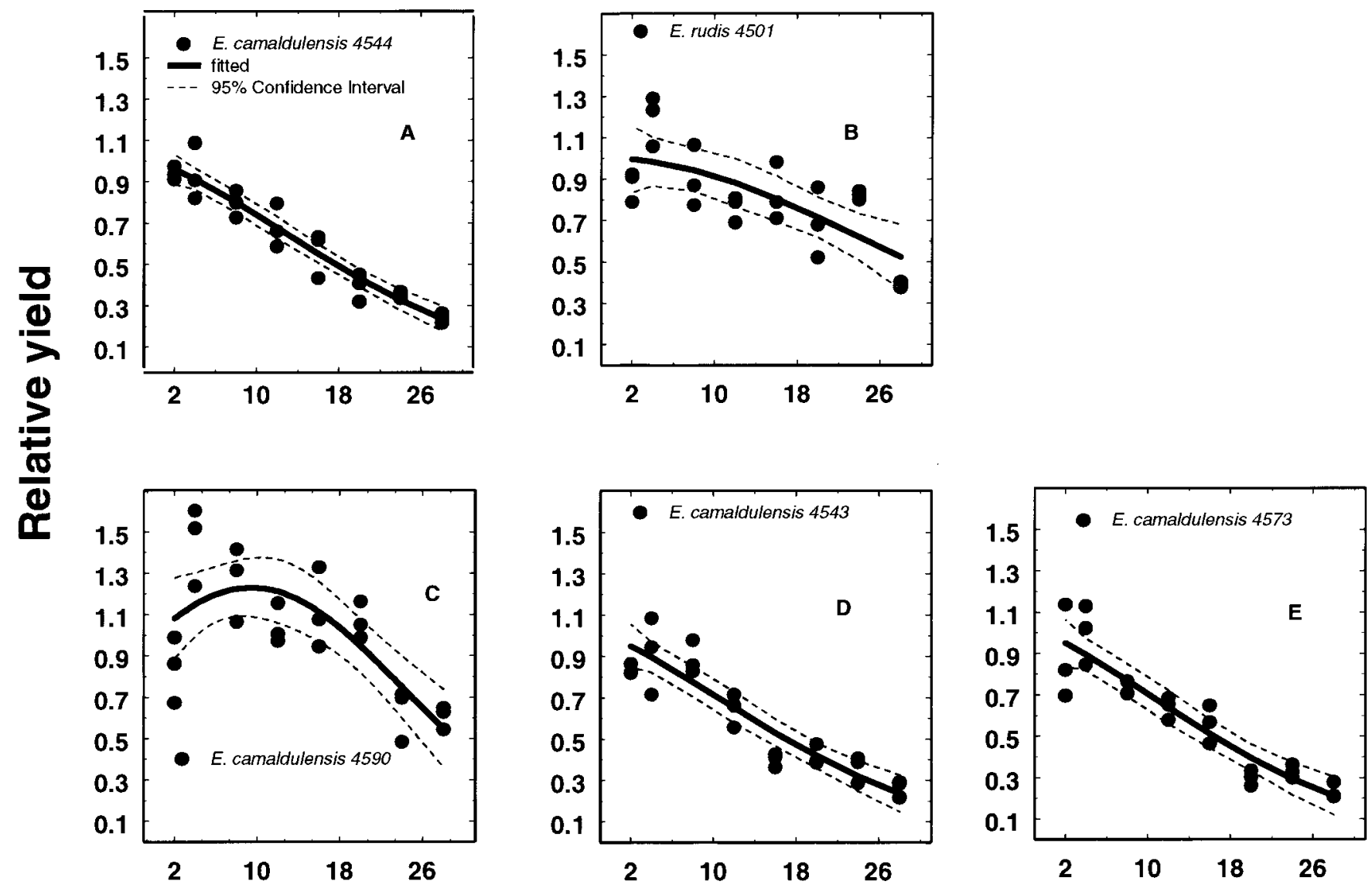

Electrical conductivity $\left(\mathrm{dSm}^{-1}\right)$

Fig. 1A-E. Relative shoot biomass production of five eucalyptus clones as a function of increasing irrigation water salinity.

surements and relative growth rate calculations, all clones grew as well or better when irrigated with waters salinized at 4 or $8 \mathrm{dS} \cdot \mathrm{m}^{-1}$ than when the control solution $\left(2 \mathrm{dS} \cdot \mathrm{m}^{-1}\right)$ was used.

Coppicing under saline conditions. Most of the remaining stumps, still irrigated with the treatment solutions, sprouted $\approx 1$ week after the initial harvest. Survival of the coppiced trees after 6 weeks was not correlated with salinity treatment (Table 2). Allender (1990) reported that E. camaldulensis coppiced reliably. This observation was borne out in the present experiment; regrowth survival across salinity treatments was higher for clones of this species than for the E. rudis clone (4501).

\section{Discussion}

In this short-term greenhouse study, the performance of all five Eucalyptus clones across salinity levels was generally in agreement with earlier results from saline field trials with other E. camaldulensis genotypes (Dunn et al., 1994; Farrell et al., 1996b) and glasshouse pot cultures (Blake, 1981; Marcar, 1989). Sands (1981) reported a high survival rate for E. camaldulensis seedlings grown for 3 months in saline $(400 \mathrm{~mm} \mathrm{NaCl})$ pot cultures. van der Moezel et al. (1991) found that E. rudis survived in sand cultures salinized at $35 \mathrm{dS} \cdot \mathrm{m}^{-1}$,

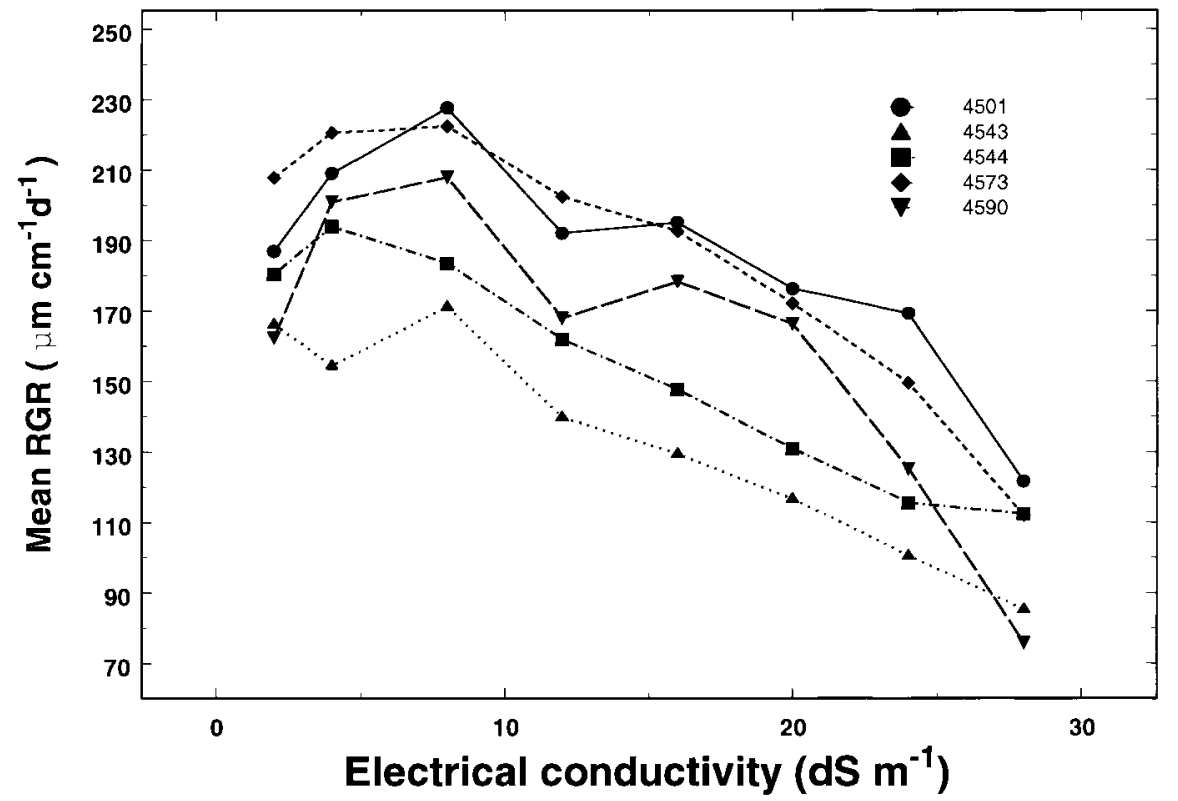

Fig. 2. Relative growth rates of eucalyptus clones $4501(\bullet), 4543(\boldsymbol{\Delta}), 4544(\boldsymbol{\square}), 4573(\bullet)$, and $4590(\boldsymbol{\nabla})$ as a function of increasing irrigation water salinity. Values are means of three replications. 
Table 2. Effects of saline irrigation waters on coppicing ability and survival of five eucalyptus clones (three trees per treatment).

\begin{tabular}{|c|c|c|c|c|c|}
\hline $\begin{array}{l}\mathrm{EC}_{\mathrm{i}} \\
\left(\mathrm{dS} / \mathrm{m}^{-1}\right)\end{array}$ & 4501 & 4543 & 4544 & 4573 & 4590 \\
\hline \multicolumn{6}{|c|}{ No. trees surviving } \\
\hline 2 & 2 & 0 & 1 & 3 & 3 \\
\hline 4 & 2 & 2 & 0 & 3 & 3 \\
\hline 8 & 2 & 2 & 1 & 0 & 2 \\
\hline 12 & 2 & 3 & 3 & 3 & 3 \\
\hline 16 & 3 & 3 & 3 & 3 & 3 \\
\hline 20 & 1 & 3 & 3 & 3 & 0 \\
\hline 24 & 2 & 3 & 3 & 3 & 0 \\
\hline 28 & 1 & 3 & 3 & 3 & 3 \\
\hline \multicolumn{6}{|c|}{ Survival $(\%)^{y}$} \\
\hline & 63 & 75 & 71 & 88 & 71 \\
\hline
\end{tabular}

${ }^{\mathrm{z}}$ After 6 weeks under saline treatment.

${ }^{y}$ Survival (\%) of each clone across all salinity levels.

although growth was reduced by $50 \%$.

Although the height and appearance of the ramets of each clonal line used for this study were exceptionally uniform at the time of planting, some clones showed unexpectedly high variation in biomass production within replications, whereas others, such as 4544 , were extremely uniform. Coefficients of variation for experimental subunits within replications were consistent within clones across salinity treatments. Presuming that the clones were genetically uniform, differences in variability might be due to different sensitivities of each genotype to environmental factors unrelated to salinity treatment. Variation in plant height among individuals of each clone was considerably less than was shoot biomass production. Coefficients of variation, ranging from $5 \%$ to $8 \%$, were similar to the mean variation $(8 \%)$ in plant height reported for $E$. camaldulensis replicate clones from different provenances (Bell et al., 1993).

Our results suggest that the five eucalyptus clones can be separated into two groups based on differences in leaf morphology and response to sodium sulfate-dominated salinity. Eucalyptus camaldulensis clones 4543, 4544, and 4573 formed one group. Their leaves are thick, glaucous, and elliptical. Based on biomass production, their $\mathrm{C}_{50}$ value was $\approx 17$ $\mathrm{dS} \cdot \mathrm{m}^{-1}$. These characters were clearly different from those of the second group, consisting of $E$. rudis clone 4501 and E. camaldulensis clone 4590. Leaves of 4501 and 4590 are thin, nonglaucous, and ovoid. Their $\mathrm{C}_{50}$ value of $\approx 29.5 \mathrm{dS} \cdot \mathrm{m}^{-1}$ was $\approx 40 \%$ higher than that of the other group. The division of these five eucalyptus clones into two well-defined groups is further corroborated by significantly distinctive patterns of ion uptake and partitioning (Grieve and Shannon, 1999).

\section{Literature Cited}

Allen, J.A., J.L. Chambers, and M. Stine. 1994 Prospects for increasing the salt tolerance of forest trees: A review. Tree Physiol. 14:843-853.

Allender, E.B. 1990. Tree species for woodlotsExisting cultivars, p. 18-22. In: Proc. Woodlots Wkshp., Ser. No. 32, compiled by Mark Dale, Mildura Function Centre, Dept. of Agr. Rural Affairs, Australia.

Bell, D.T., P.G. van der Moezel, I.J. Bennett, J.A. McComb, C.F. Wilkins, S.C.B. Marshall, and A.L. Morgan. 1993. Comparisons of growth of Eucalyptus camaldulensis from seeds and tissue culture: Root, shoot and leaf morphology of 9month-old plants grown in deep sand and sand over clay. For. Ecol. Mgt. 57:125-139.

Blake, T.J. 1981. Salt tolerance of eucalypt species grown in saline solution culture. Austral. For. Res. 11:179-183.

Cervinka, V. 1994. Agroforestry farming system for the management of selenium and salt on irrigated farmland, p. 237-250. In: W. Frankenberger, Jr. and S. Benson (eds.). Selenium in the environment. Marcel Dekker, New York.

Dell, B. 1995. Diagnosis of nutrient deficiencies in eucalypts, p. 417-440. In: P.M. Attiwill and M.A. Adams (eds.). Nutrition of eucalypts. Cmwlth. Sci. Ind. Res. Council, Div. of Soils, Collingwood VIC, Australia.

Donaldson, D.R., J.K. Hasey, and W.B. Davis. salty, flooded soils. Calif. Agr. 37(9\&10):20-21.

Dunn, G.M., D.W. Taylor, M.R. Nester, and T.B. Beetson. 1994. Performance of twelve selected Australian tree species on a saline site in southeast Queensland. For. Ecol. Mgt. 70:255-264.

Eldridge, K., J. Davidson, C. Harwood, and G. van Wyk. 1993. Eucalypt domestication and breeding. Clarendon Press, Oxford.

Farrell, R.C.C., D.T. Bell, K. Akilan, and J.K. cal comparisons of clonal lines of Eucalyptus camaldulensis. I. Responses to drought and waterlogging. Austral. J. Plant Physiol. 23:497-507.

Farrell, R.C.C., D.T. Bell, K. Akilan, and J.K. 1983. Eucalyptus out-perform other species in Marshall. 1996a. Morphological and physiologi-
Marshall. 1996b. Morphological and physiological comparisons of clonal lines of Eucalyptus camaldulensis. Responses to waterlogging/salinity and alkalinity. Austral. J. Plant Physiol. 23:509-518.

Grieve, C.M. and M.C. Shannon. 1999. Ion accumulation and distribution in shoot components of salt-stressed eucalyptus clones. J. Amer. Soc. Hort. Soc. 124:559-563.

James, S.A. and D.T. Bell. 1995. Morphology and anatomy of leaves of Eucalyptus camaldulensis clones: Variation between geographically separated locations. Austral. J. Bot. 43:415-433.

Low, C.B., G.H. Matson, and R.M. Sachs. 1983. Propagating fast-growing eucalypts for energy crops. Calif. Agr. 37(5\&6):20-21.

Marcar, N.E. 1989. Salt tolerance of frost-resistant eucalypts. New For. 3:141-149.

Marcar, N.E. and D. Crawford. 1996. Tree-growing strategies for the productive use of saline land. Austral. J. Soil Water Conserv. 9:34-40.

Marcar, N.E., K.G. Eldridge, V.J. Hartney, and B.J. Myers. 1990. Tree species for woodlots: Future cultivars, p. 23-30. In: Proc. Woodlots Wkshp., Ser. No. 32. Mildura Function Centre, Dept. Agr. Rural Affairs, Victoria, Australia.

Myers, R.H. 1990. Classical and modern regression with applications. Duxbury Press, Belmont, Calif.

Poorter, H. 1989. Plant growth analysis: Towards a synthesis of the classical and the functional approach. Physiol. Plant. 75:237-244.

Rhoades, J.D. 1989. Intercepting, isolating, and reusing drainage waters for irrigation to conserve water and protect water quality. Agr. Water Mgt. 16:37-52.

Sands, R. 1981. Salt resistance of Eucalyptus camaldulensis Dehn. from three different seed sources. Austral. For. Res. 11:93-100.

San Joaquin Valley Drainage Program. 1990. A management plan for agricultural subsurface drainage and related problems on the westside San Joaquin Valley. Final Report. E.A. Imhoff, Mgr., Calif. Dept. Water Resources. Sept. 1990.

SAS Institute. SAS user's guide: Statistics. 1985. ver. 5. Proc NLIN. SAS Inst., Cary, N.C.

Shannon, M.C. and C.M. Grieve. 1999. Options for using poor-quality water for vegetable crops. HortScience. (In press.)

Thomson, L.A.J. 1988. Salt tolerance of Eucalyptus camaldulensis and related species. PhD Diss., Univ. of Melbourne, Australia. (Cited in Allen et al., 1994.)

Thornley, J.H.M. 1990. A new formulation of the logistic growth equation and its application to leaf area growth. Ann. Bot. 66:309-311.

van der Moezel, P.G., G.V.N. Pearce-Pinto, and D.T. Bell. 1991. Screening for salt and waterlogging tolerance in Eucalyptus and Melaleuca species. For. Ecol. Mgt. 40:27-37.

van Genuchten, M. Th. and G.J. Hoffman. 1984. Analysis of crop salt tolerance data. p. 258-271. In: I. Shainberg and J. Shalhevet (eds.). Soil salinity under irrigation: Processes and management. Ecol. Studies 51. Springer-Verlag, New York. 